\title{
INCREASING EFFICIENCY OF AN I.C. ENGINE USING STEAM CHARGING TECHNIQUES
}

\author{
L. Sunil premkumar ${ }^{1}$, M. Vignesh ${ }^{2}$, M. Suresh ${ }^{3}$ \\ ${ }^{1}$ U.G. Student, Mechanical Engineering, SNS College of Engineering, Tamil Nadu, India \\ ${ }^{2}$ U.G. Student, Mechanical Engineering, SNS College of Engineering, Tamil Nadu, India \\ ${ }^{3}$ U.G. Student, Mechanical Engineering, SNS College of Engineering, Tamil Nadu, India
}

\begin{abstract}
The focus of this study is based on increasing efficiency of an internal combustion engine, by using exhaust gas temperature. Turbo charging and super charging techniques are already in use in some of the vehicles, there charging is carried out in internal combustion engine by means of kinetic energy of exhaust gas. Here we pioneer exhaust gas heat recovery by steam turbocharging technique. This method will give solution to some problems happened by over heat generation of exhaust gas. The increasing worldwide problem regarding rapid economy development and a relative shortage of energy, the internal combustion engine exhaust waste heat and environmental pollution has been more emphasized heavily recently. Out of the total heat supplied to the engine in the form of fuel, approximately, 30 to $40 \%$ is converted into useful mechanical work; the remaining heat is expelled to the environment through exhaust gases and engine cooling systems, resulting in to entropy rise and serious environmental pollution, so it is required to utilized waste heat into useful work. It also reduces the amount of waste heat and greenhouse gases damped to environment. It describes loss of exhaust gas energy of an internal combustion engine. It provide the possible method to recover the waste heat from internal combustion engine and performance of the internal combustion engine. Steam turbo charging technique is the best way to recover waste heat and to improve the efficiency of an IC engine by 10 to 20 percentage
\end{abstract}

Keywords: operating tower ${ }^{l}$ - a set of arrangement for the passage of steam to get required velocity of steam jet; boiler $^{2}$ - a container where evaporation takes place; working fluid ${ }^{3}$ - operating medium; turbocharger ${ }^{4}-$ a device

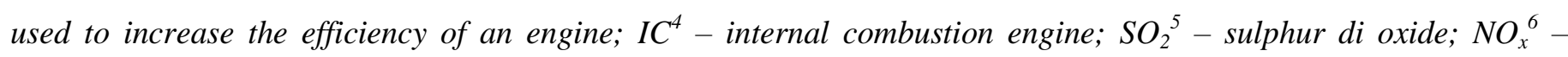
nitrogen oxides.

\section{INTRODUCTION}

In this method we mainly concentrate about increasing efficiency of an I.C. engine and to reduce the exhaust toxic gases. Both the problems are caused due to improper fuel mixture ratio and improper burning in the engine. To do this, supercharger and turbocharger are already exists in vehicles. In turbocharger the kinetic energy of exhaust gas is used to get energy for compression of existing air. In super charger it gets energy from energy of engine, so it is no so economical. We analyzed the temperature of exhaust gases from several diesel and petrol engines, as per table 1. Then we pioneered a new idea that increasing efficiency of an engine by using heat from the exhaust gas.

\subsection{Features}

This method consists of an evaporator unit, turbine unit, compressor unit, nozzle and a cooling unit with steam exchangeable tubes.

Table - 1: Exhaust gas temperature of engines.

\begin{tabular}{|l|l|l|}
\hline S.no & Engines & $\begin{array}{l}\text { Temperature } \\
\text { range } \\
\text { (Celsius) }\end{array}$ \\
\hline 1 & Petrol engines & $500-600$ \\
\hline
\end{tabular}

\begin{tabular}{|l|l|l|}
\hline 2 & $\begin{array}{l}\text { Single cylinder four stroke } \\
\text { diesel engine }\end{array}$ & 456 \\
\hline 3 & $\begin{array}{l}\text { Four cylinder four stroke } \\
\text { diesel engine (TATA } \\
\text { Indica) }\end{array}$ & 448 \\
\hline 4 & $\begin{array}{l}\text { Six cylinder four stroke } \\
\text { diesel engine (TATA } \\
\text { Truck) }\end{array}$ & 336 \\
\hline 5 & $\begin{array}{l}\text { Four cylinder four stroke } \\
\text { diesel engine (Mahindra } \\
\text { Arjun 605 DI) }\end{array}$ & 310 \\
\hline 6 & $\begin{array}{l}\text { Genset (Kirloskar) } \\
\text { Genset (Cummins) }\end{array}$ & 383 \\
\hline
\end{tabular}

(Ref. - This temperature was taken from survey of various internal combustion engines.)

\subsection{Working Principle}

A boiler in which steam is generated have constant pressure. That pressurized steam is sealed up to certain pressure limit. When the limit is reached the spring valve which seals the steam is compressed and give way to steam, to enter the nozzle. An engine or turbine in which the kinetic energy of the steam is utilized to produce the mechanical energy 


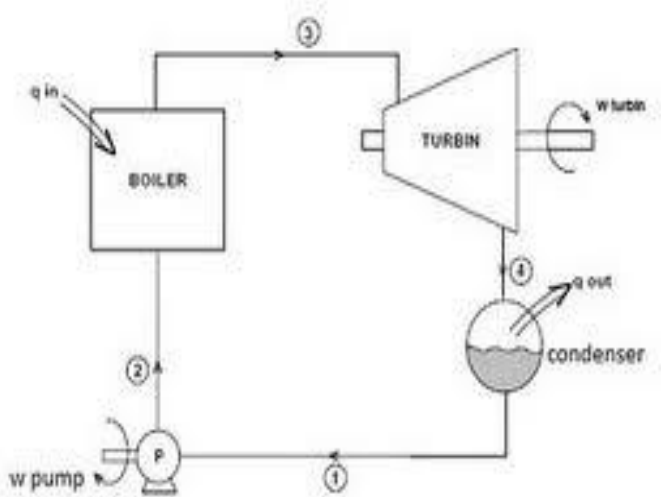

Fig - 1: working cycle

A condenser in which the exhaust steam discharged from the engine is converted into water. The condensed water from the condenser is recollected in a hot well. Here the hot well is cylindrical boiler arrangement.

Like any other steam turbine cycles, the pump for circulating water is avoided.

\section{COMPONENTS}

\subsection{Working Fluid}

The working fluid for steam engine cycle should be cheap, universally available, chemically stable and harmless.

It must have small specific heat of liquid. This will render the sensible heat negligible in comparison to heat added for boiling which is added at the upper temperature. It should have highest saturation temperature for a moderate pressure

Case 1: In case of mercury is concerned it is used as a topping fluid in binary plants. But it is costly and poisonous.

Case 2: In case if we select water it has critical temperature and pressure as 374 degree Celsius and 220.724 bar respectively. It is readily available, chemically stable, cheap and hazardless.

In both the cases we consider above, we select water as a working fluid.

\subsection{Evaporator Unit}

It is simply a hollow cylindrical unit. It has three passages. One for allowing water into the cylinder whereas second one for operating tower passage.

And the last passage for safety. It acts as a safety valve if any undesirable changes happened in the operating passage or pressure releasing valve or nozzle; it causes the increased pressure atmosphere inside the cylinder leads to burst the cylinder. This is avoided by this passage.

\subsection{Evaporator Cylinder}

It is a hollow cylindrical arrangement it have a capacity to hold the water up to one litre. The cylinder is made up to highly thermal conductive material. For certain extents the fluid inside the cylinder starts boiling and then to evaporating.

\subsubsection{Effect of Pressure on Boiling Point}

The temperature at which water boils depends upon the pressure. As the pressure increases, the boiling temperature of water increases.

For every pressure there is a definite temperature at which water begins to boil. The temperature of water at a particular pressure is known as saturation temperature.

\subsubsection{Effect of Temperature on Pressure}

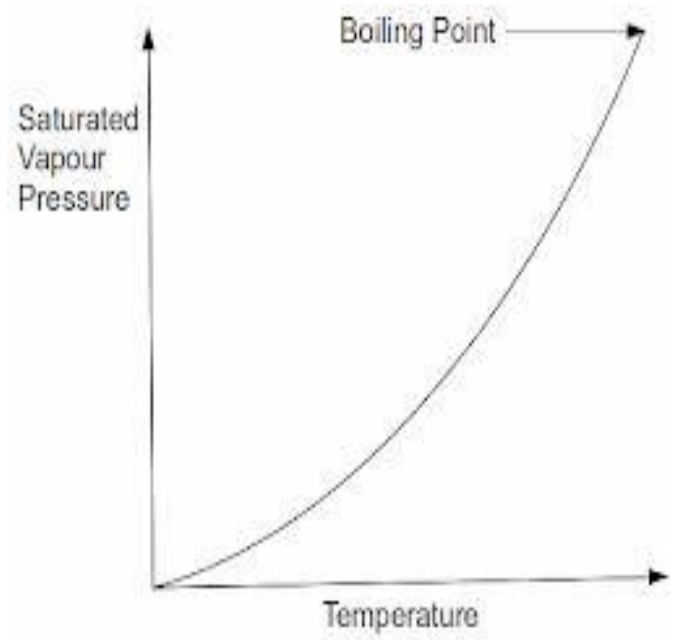

Fig - 2: Temperature vs. pressure (From reference [6])

Steam is generated from water at a certain pressure which is almost higher than atmospheric pressure. Hence temperature is directly proportional to pressure, as the temperature increases pressure also increases as shown in figure 2 .

\subsection{Operating Tower}

It is a tube like arrangement leads from the evaporator cylinder. As the pressure inside the cylinder increases it tower. The pressurized steam is sealed up to certain pressure limit. When the limit is reached the spring valve which seals the steam is compressed and gives way to steam to enter the nozzle. At the end of the tube arrangement a constant pressure fluid reliever is attached.

The constant pressure fluid reliever releases the fluid with certain pressure. That is called as operating pressure. The pressure with fluid below the operating pressure is opposed by the reliever.

By setting this arrangement we can allow a constant pressure inside the turbine unit. Between the turbine and reliever unit a nozzle is present. Further, the operating tower is made up of nimonic alloy for withstand high temperature and corrosion hazards. 


\subsubsection{Spring}

On selecting a spring we have to consider the following factors:

1. The range of stress through which the spring operation

2. The environmental conditions in which the spring will operate such as temperature and corrosive atmosphere.

3. The severity of deformation encountered while making the spring.

On the basis of above conditions stainless steel springs are considered for our equipment. Because it is free from corrosive conditions, high temperature resistant and highly sensitive.

The deflection is the main factor on designing a spring Equation 1: Deflection $=8 *$ operating pressure $*$ diameter of spring * number of turns / modulus of rigidity*fourth power of diameter of wire of spring. Reference [10]

Equation 2: stiffness = load or pressure / deflection According to equation 1 and 2 the deflection is adjusted by setting spring with correct required stiffness based on limiting pressure.

\subsection{Nozzle}

The nozzle unit converts the high pressure steam into high velocity steam. The nozzle ring is where the energy in the exhaust gas is converted into kinetic energy. It is fabricated from a creep resistant chromium nickel alloy, heat resisting moly-chrome nickel steel or a nimonic alloy which will withstand the high temperatures and be resistant to corrosion.

Equation 3: Velocity of steam discharging from outside of nozzle $=$ square root of enthalpy change

\subsection{Steam Turbine}

The jet of nozzle steam is allowed to impart the turbine blade. The turbine blades are well designed to run the blades with maximum velocity.

Turbine blades are usually a nickel chrome alloy or a nimonic material (a nickel alloy containing chrome, titanium, aluminium, molybdenum and tungsten) which has good resistance to creep, fatigue and corrosion. Nowadays turbine blades are made up of Inconel alloys. It is manufactured using the investment casting process. Blade roots are of fir tree shape which gives positive fixing and minimum stress concentration at the conjunction of root and blade. The root is usually a slack fit to allow for differential expansion of the rotor and blade and to assist damping vibration. On small turbochargers and the latest designs of modern turbochargers the blades are a tight fit in the wheel. Whatever may be the losses due to friction is concerned the velocity is decreased to certain value. The steam turbine is an impulse turbine type. The steam turbine is connected to compressor unit by means of shaft.

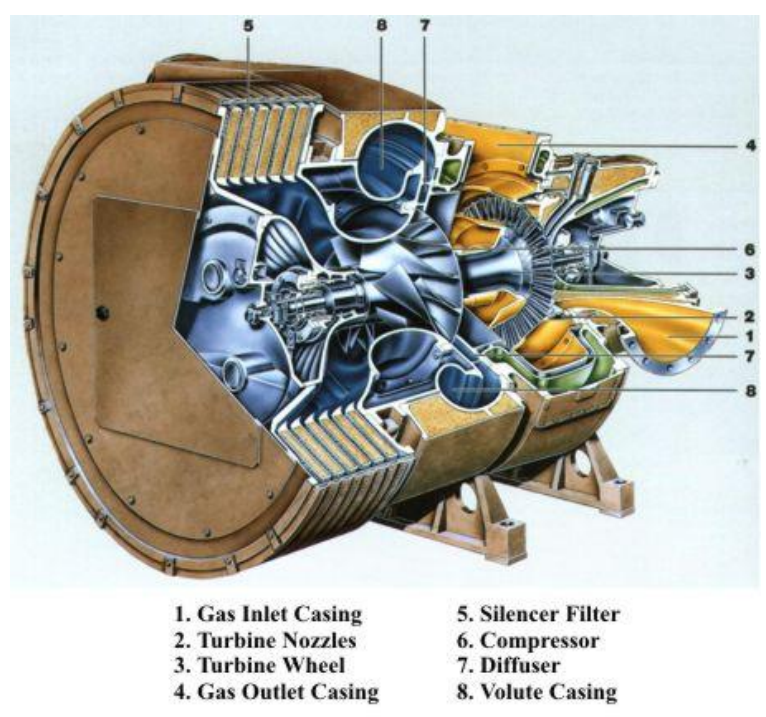

Fig - 3: Internal parts of turbocharger

\subsection{Compressor Unit}

The compressor is a centrifugal type. The compressor is rotated with respect to the rotation of the turbine which is already connected to turbine by shaft.

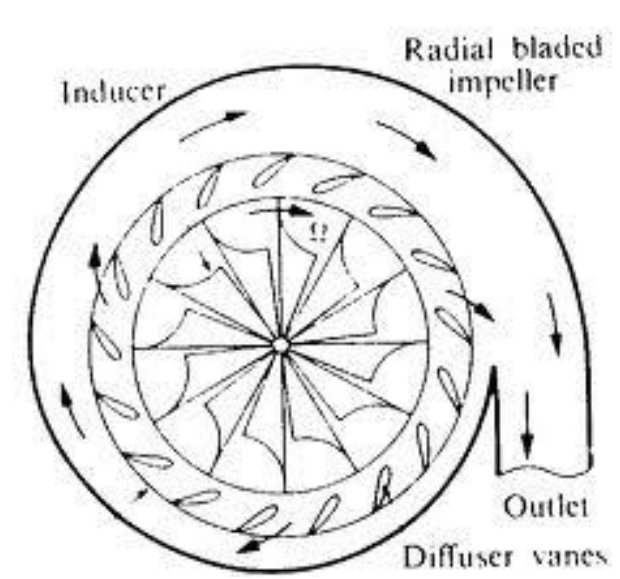

Fig - 4: Centrifugal compressor

\subsection{Condensation Unit}

The most important unit in this steam turbocharger is condensation unit. In this one the steam is converted into water by means of cooling. Initially the latent heat of steam is released by cooling and further its temperature is decreased. Slowly the water vapor is converted into liquid.

\subsection{Water Level Indicator}

This unit is used for safety purpose. Whatever may be a recycling reaction, some amount of water will evaporate, so a steady decrease in the water level will happen and finally it emptied the boiler. So this is avoided and indicated by water level sensor. 


\section{FACTORS AFFECTING LIFE OF A STEAM TURBO CHARGER}

The expected life of a turbocharger can be influenced by a number of factors. One categorization of steam turbocharger failures is as follows:

1. Thermal cracking, creep or oxidation of parts

- Cracked turbine housing.

- Rubbing or distortion of turbine housings due to over-heating.

- Compressor housing distortion due to over-heating.

- Compressor wheel failure due to creep.

2. Fatigue of rotating parts

- Cracked compressor wheel.

- Cracked turbine wheel.

- Turbine wheel blade loss.

3. Structural failure of the turbocharger or attached parts

- Loose bolts.

- Cracked flanges.

4. Fatigue stress of spring in tower due to repetitive expansion and compression of variable pressure.

While many of the above failures are outside the control of the turbocharger designer, others can be avoided or minimized through the turbocharger design process or by observing application limits. Some parameters that can be limited to avoid the failures mentioned above include:

1. Turbocharger speed

2. Temperature

○ Turbine inlet temperature.

- Compressor outlet temperature.

3. Structural loads

- External load limitations.

$\circ \quad$ Weight and torque reaction of external parts.

- Maximum vibration levels.

- Built in stresses due to assembly.

\section{CONCLUSIONS}

From the study it has been identified a large potential energy is saved by waste energy recovery system. We assure that, this technology will improve the efficiency of an internal combustion engine. By increasing the efficiency of the IC engine the emission of $\mathrm{NOx}, \mathrm{SO}_{2}$ and dangerous gas can be avoided by perfect ignition. It has been observed that the life time of a catalytic convertor can be increased to certain extent because a little amount of temperature is used here for boiling the water. We expected that the efficiency can be increased to 5 to 10 percent.

\section{REFERENCES}

[1]. Dolton, M., 2006. "The Use of Limits in Applying Turbochargers to Engines", HTi Magazine

[2]. "Engineering thermodynamics" by P.K. Nag

[3]. "Thermal engineering" by Sarkar

[4]. Dexclaux, Jacques and Serre, Jacque (2003). "M88-2

E4: Advanced New Generation Engine for Rafale Multirole

Fighter". AIAA/ICAS International Air and Space
Symposium and Exposition: The Next 100 Years. 14-17w July 2003, Dayton, Ohio

[5]. Magyar, Michael J. "Mineral Yearbook: Rhenium" (PDF). United States Geological Survey.

[6]. YAHYA, SM (2011). "Chapter 10: High temperature (cooled) turbine stages". Turbines, compressor and fans (4th Ed.). New Delhi: Tata McGraw Hill Education private limited.

[7]. Flack, Ronald D. (2005). "Chapter 8: Axial Flow Turbines". Fundamentals of Jet Propulsion with Applications. Cambridge Aerospace Series. New York, NY: Cambridge University Press.

[8]. Sachdeva "Fundamentals of Engineering Heat and Mass Transfer"

[9]. "Technologies to recover exhaust heat energy" by Dr. Saidur

[10]. Design of machine elements V.B. BHANDHARI [] Chicago 